\begin{tabular}{|c|c|c|c|c|c|c|}
\hline \multirow{4}{*}{ Impact Factor: } & ISRA (India) & $=3.117$ & SIS (USA) & $=0.912$ & ICV (Poland) & $=6.630$ \\
\hline & ISI (Dubai, UAI & $=0.829$ & РИНЦ (Russia) & $=0.156$ & PIF (India) & $=1.940$ \\
\hline & GIF (Australia) & $=0.564$ & ESJI (KZ) & $=5.015$ & IBI (India) & $=4.260$ \\
\hline & JIF & $=1.500$ & SJIF (Morocco) & $=5.667$ & & \\
\hline
\end{tabular}

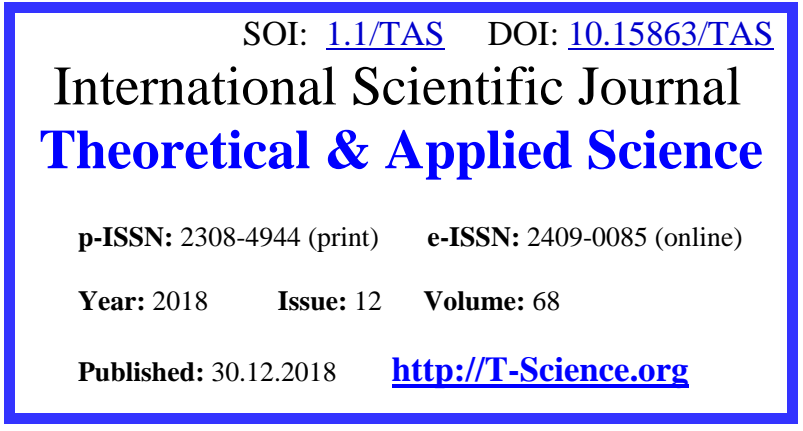

QR - Issue

QR - Article

SECTION 32. Jurisprudence.
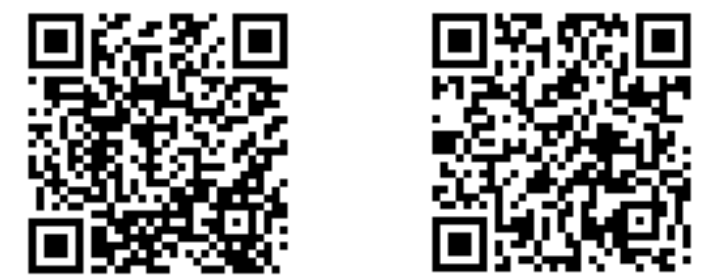

Iskandar Kamalovich Yusupaliev candidate of juridical science assistant professor of department "KandCE" of Osh governmental juridical institute Osh city of Kyrgyz Republic

\title{
THE LEGAL STATUS OF THE EXPERT CRIMINALIST IN CRIMINAL PROCEEDINGS
}

\begin{abstract}
This article emphasizes the general status of experts as persons acquiring this status as a result of the appointment of examinations in specific criminal cases directly by the investigators or the courts. In addition, the author analyzed the reasons for the refusal of the examination.

Key words: law, expert, criminal, legal proceedings, examination, status.

Language: Russian

Citation: Yusupaliev, I. K. (2018). The legal status of the expert criminalist in criminal proceedings. ISJ Theoretical \& Applied Science, 12 (68), 88-91.

Soi: $\underline{\text { http://s-o-i.org/1.1/TAS-12-68-18 Doi: crossef https://dx.doi.org/10.15863/TAS.2018.12.68.18 }}$

\section{ПРАВОВОЙ СТАТУС ЭКСПЕРТА-КРИМИНАЛИСТА В УГОЛОВНОМ СУДОПРОИЗВОДСТВЕ}

Аннотация: В данной статье подчеркивается общий статус экспертов как лиц приобретающих этот статус вследствие назначения экспертиз по конкретным уголовным делам непосредственно следователями или судами. Кроме этого автором проанализированы причины отказа от производства экспертиз.
\end{abstract}

Ключевые слова: право, эксперт, уголовный, судопроизводство, экспертиза, статус.

\section{Introduction}

На основе глубокого социальноэкономического преобразования происходящего в республике за последнее время заметна криминализация общества с ростом и видоизменением структуры преступлений.

Участники преступной деятельности путем совершенствования используемых методов, приемов и средств для осуществлений нарушений прав мирного населения, с целью нанесения им вреда здоровью или смерти. Они являются организованными, технически оснащенными, в расположении имеют значительную материальную базу, что существенно может осложнить процессы выявления и расследования преступления. В таких условиях для доказывания по уголовному делу значительно повышается роль использования специального знания.

Экспертиза производится экспертом сведущим лицом, обладающим важными специальными знаниями в области науки, техники или ремесла.
Экспертами производятся экспертные исследования в соответствии с их специальными знаниями и на их основе даются заключения эксперта, за которые они несут личную ответственность. Вышесказанные положения определяют что, экспертами могут быть лица, назначаемые органами следствия или судом, обладающие соответствующие научные, технические или другие специальные знания, применение которых разрешает вопрос, возникающий при производстве по уголовным делам.

\section{Materials and Methods}

Практика судебной экспертизы обязывает наличие у экспертов достаточной компетенции, то есть навыки, образование, опыт и знания, необходимые для производства объективного заключения и ответа на поставленный вопрос [2]. Вследствии этого, приобретенный в результате назначений судебной экспертизы статус экспертов условно разделяется на три статуса: общий статус, специальный и индивидуальный. 


\begin{tabular}{|c|c|c|c|c|c|c|}
\hline \multirow{4}{*}{ Impact Factor: } & ISRA (India) & $=3.117$ & SIS (USA) & $=0.912$ & ICV (Poland) & $=6.630$ \\
\hline & ISI (Dubai, UAE & $=0.829$ & РИНЦ (Russia) & $=0.156$ & PIF (India) & $=1.940$ \\
\hline & GIF (Australia) & $=0.564$ & ESJI (KZ) & $=\mathbf{5 . 0 1 5}$ & IBI (India) & $=4.260$ \\
\hline & JIF & $=1.500$ & SJIF (Morocco) & $=5.667$ & & \\
\hline
\end{tabular}

Общим статусом экспертов лица приобретают вследствие назначения экспертиз по конкретным уголовным делам непосредственно следователями или судами. Правовое положение экспертов и порядок проведения экспертиз в государственных

судебно-экспертных учреждениях регламентируется Уголовнопроцессуальным кодексом от 4 декабря 2017 г. № 198, а так же законом Кыргызской Республики «O государственной судебно-экспертной деятельности» от 10 февраля 2017 года № 98

Успешное решения задачи, поставленной перед экспертами, предполагает в законодательстве Кыргызской Республики образования системы прав и обязанностей экспертов. УПК Кыргызской Республики предоставляет им соответствующие права [1]:

a) на ознакомление с материалом уголовного дела, относящимся к предмету экспертизы (ст. 63 УПК КР). Осведомление экспертов об обстоятельстве и материале дела является важным обстоятельством успешного проведения экспертиз. Как известно экспертной практике экспертам не всегда нужно знать все материалы уголовных дел, поскольку предмет экспертизы не всегда может быть связан всеми материалами дела и могут привести лишь к ненужным затратам силы и времени экспертов.

б) на ходатайство о предоставлении им дополнительного материала, необходимого для дачи заключений (п. 3 ст. 63 УПК КР);

в) на присутствие с разрешением следователей, судов при производстве следственного или судебного действия, задавать допрашиваемому вопрос, имеющий отношение к предметам экспертизы (п.5. ст. 63 УПК КР); При производстве исследования иногда могут возникать необходимость в получении дополнительных данных, которые не всегда могут быть сообщены экспертам путем направления еим материалов, вследствие которых возникают потребности личного осмотра обстановки мест происшествий.

г) на указание в своих заключения на обстоятельство, о котором им не был поставлен вопрос, если это обстоятельство имеет значение для установления истины по делам (ст. 84 УПК KP);

д) на изложение на допросе своих показаний собственноручно (ст. 210 УПК КР);

е) на дачу заключения и показание на родном языке, в случае не владения языком судопроизводства (ст. 23 УПК КР);

ж) на отказ от дачи заключений, если поставленный вопрос выходит за пределы их специальных знаний (ст. 63 УПК КР);

3) на участие в судебных разбирательствах по вопросу, относящимся к предметам экспертизы (ст.63 УПК КР).
Предоставленный материал может быть возвращен экспертами следователям или суду без исполнения, но они обязательно должны обеспечить письменным обоснованием свои действия.

Причинами отказа от производства экспертиз могут быть следующие:

1) ошибка в направлении материалов в СЭУ;

2) отсутствие условия и средства проведения экспертиз в экспертных учреждениях;

3) недостаточное количество представленного материала для производства заключения;

4) отсутствие необходимой методики исследования.

В процессуальную обязанность эксперта входит проведение полных, всесторонних исследований на подлинно научных основах, с целью дачи объективных заключений [3]. Новый УПК Кыргызстана, принятый 4 декабря 2017 года включает в себя следующие обязанности судебных экспертов:

1) являться по вызову следователей и судов (ст. 63 п.1 УПК КР);

2) давать объективное заключение по поставленному вопросу (ст. 63 п. 2 УПК КР);

3) не разглашать материал следствия;

4) не нарушать порядок при производстве следственного действия и во время судебных заседаний.

Проведенный анализ специфики реализации экспертной функции в процессе производства экспертиз, нормативного акта [4], устанавливающего регламент отдельного вида экспертизы, позволило определить следующие условия по допуску экспертов к производству экспертизы:

1) компетентность экспертов;

В данной ситуации понятие «компетентности» нужно рассматривать как совокупность специальных познаний, прав и обязанностей лица, которому поручено проведение экспертизы. То есть эксперты должны оправдывать свое звание и должны быть опытными и сведущими лицами (expertus, от лат. опытный, сведущий) [5].

2) незаинтересованность экспертов в исходах дела;

Если эксперты не заинтересованы в исходах дела, это означает отсутствие у них побудительного мотива для дачи заведомо ложных заключений. Эксперты при решении поставленного перед ним задачи должны быть объективными.

3) процессуальная независимость экспертов и их автономность;

Это говорит о том, что эксперты являются независимыми от должностного лица и органа, проводящего расследование, а также судов. Не 


\begin{tabular}{|c|c|c|c|c|c|c|}
\hline \multirow{4}{*}{ Impact Factor: } & ISRA (India) & $=3.117$ & SIS (USA) & $=0.912$ & ICV (Poland) & $=6.630$ \\
\hline & ISI (Dubai, UAI & $=0.829$ & РИНЦ (Russia) & $=0.156$ & PIF (India) & $=1.940$ \\
\hline & GIF (Australia) & $=0.564$ & ESJI (KZ) & $=5.015$ & IBI (India) & $=4.260$ \\
\hline & JIF & $=1.500$ & SJIF (Morocco) & $=5.667$ & & \\
\hline
\end{tabular}

допускается воздействие на экспертов в целях получения заключения в пользу кого-либо из участника процесса со стороны судов, представителя органа следствия, прокурора, а также со стороны какой-либо государственной и общественной организации, должностного лиц и граждан [6].

4) наличие в уголовных делах специальных решений правоохранительных органов о привлечении данных лиц в качестве экспертов.

Необходимыми правовыми предпосылками участия экспертов в производствах экспертиз являются назначения экспертиз органами следствия, прокурорами и судами. Эксперты становятся участниками процесса с момента вынесения следователями постановления о назначении экспертизы, поскольку эти обстоятельства являются юридическими фактами, позволяющие экспертам реализовать принадлежащие им по закону процессуальные права и обязанности [7].

Вместе с правами законодательство так же определяет обязанности экспертов, а также меры и виды ответственности, которые могут быть применены в случае их нарушения. В процессе экспертизы эксперты обладают процессуальной независимостью и автономностью, дают заключения от своего имени и несут за него личную ответственность [8]. В случае отказа или уклонения от дачи заключения Уголовный кодекс Кыргызской Республики предусмотрел уголовную ответственность экспертов. Необходимо заметить, что данная норма фактически не работает, вследствие неправильных оценок компетентности экспертов.

Для обеспечения объективности, достоверности экспертных заключений, за дачу заведомо ложного заключения эксперты несут ответственность в соответствии со ст. 330 Уголовного кодекса КР. Вместе с тем на практике практически не встречается случай привлечения экспертов к уголовной ответственности по указанной статье ввиду крайней сложности доказывания факта дачи заведомо ложного заключения, а не добросовестных заблуждений экспертов. В экспертной практике встречается ошибочное заключение, которое дается вследствие неглубоких, поверхностных исследований экспертов. Такое заключение на практике, как правило, устраняется следователями и судами путем назначений повторноых экспертиз.

За разглашение данных предварительного расследования для экспертов предусмотрена ответственность в соответствии со ст. 333 Уголовного кодекса КР.

Проведенные анализы практики показывают, что эксперты, знакомясь с обстоятельствами уголовных дел, исследуя вещественное доказательство, с учетом своего опыта и специальных познаний могут иногда объемнее, чем следователи или суды, определить круг задач, подлежащих разрешению и устанавливает другие обстоятельства, которые имеют значение для дел.

Весьма существенная роль принадлежит инициативе экспертов в делах профилактики преступлений. «Экспертная профилактика, пишет И.А. Алиев, - сложное системное образование. Основу его составляет деятельность экспертов, которые на базе своих специальных познаний выявляют обстоятельства, фигурирующие в качестве условий, а иногда и причин совершения преступлений. Выявление подобных обстоятельств может осуществляться как в процессе производства экспертизы, так и в ходе обобщения экспертной практики по мере ее накопления» [9].

Специальный статус экспертов устанавливается их образовательными уровнями, специальной экспертной подготовкой, стажем экспертных работ и иным характеризующим фактором.

В связи с тем, что экспертами могут быть назначены любые физические лица, обладающие специальным знанием, процессуальное право оставляет без внимания не только вопросы о личности экспертов, но и о спецификах экспертной деятельности как самостоятельного вида деятельности [10].

\section{Conclusion}

Эксперты

совершенствовании заинтересованы в профессионального мастерства, которое не смогло формально закрепиться. Потому что объективность, всесторонность и полнота исследований, которые должны обеспечиваться при проведении экспертами, полностью соответствуют целям и задачам уголовного судопроизводства, но все равно требования о регулярных пересмотрах уровней профессиональной подготовки эксперта косвенным образом обязывают тех, кто желает работать в государственном судебно-экспертном учреждении, совершенствовать свою квалификацию. Стремления к повышениям уровня профессионализма являются законными интересами самих экспертов.

На основе вышеуказанных данных устанавливаются правовые статусы экспертовкриминалистов, как самостоятельныхо участников уголовного судопроизводства:

\section{Потребности:}

- в обеспечении собственной безопасности;

- в предоставлении комфортных условий труда; 


\begin{tabular}{|c|c|c|c|c|c|c|}
\hline \multirow{4}{*}{ Impact Factor: } & ISRA (India) & $=3.117$ & SIS (USA) & $=0.912$ & ICV (Poland) & $=6.630$ \\
\hline & ISI (Dubai, UAI & $=0.829$ & РИНЦ (Russia) & $=0.156$ & PIF (India) & $=1.940$ \\
\hline & GIF (Australia) & $=0.564$ & ESJI (KZ) & $=5.015$ & IBI (India) & $=4.260$ \\
\hline & JIF & $=1.500$ & SJIF (Morocco) & $=5.667$ & & \\
\hline
\end{tabular}

- в автоматизации труда (что, несомненно, сокращает временные затраты на производство экспертизы);

\section{Права:}

- доступность ко всем необходимым сведениям для составления полного, всестороннего, объективного заключения;

- иметь возможность ознакомления с общей практикой по своей экспертной специальности;

- возможность свободного обмена опытом как с коллегами в Кыргызстане, так и в зарубежных странах;
- на самостоятельное внедрение новейших научно-технических разработок по имеющейся экспертной специальности, соответствующих методикам проведения экспертиз.

\section{Обязанности:}

- придерживаться профессиональным этическим нормам, в ходе общения со сторонами по делу и проведения судебной экспертизы;

- сообщать лицу или органу, назначившему экспертизу, а также руководству судебноэкспертного учреждения о фактах, способах и формах оказываемого на эксперта давления.

\section{References:}

1. (2017). Ugolovno-protsessualnyiy kodeks KR ot 4 dekabrya 2017 g. \# 198.

2. (2017). Zakon $\mathrm{KR} « O$ gosudarstvennoy sudebno-ekspertnoy deyatelnosti» $\mathrm{V}$ redaktsii zakona KR ot 10 fevralya 2017 goda \# 98

3. Maylis, N. P. (2015). Vvedenie v sudebnuyu ekspertizu. uchebnoe posobie. Moskva: YunitiDana.

4. Moiseeva, T. F. (2016). Osnovyi sudebnoekspertnoy deyatelnosti. konspekt lektsiy. Moskva: Ros. gos. un-t pravosudiya.

5. Averyanova, T. V. (2009). Sudebnaya ekspertiza [Tekst]: kurs obschey teorii. Moskva: Norma.

6. Gvozdeva, I. S. (2008). Ispolzovanie spetsialnyih znaniy pri rassledovanii prestupleniy. Krasnodar: Kuban. gos. agrar. unt.

7. Evstigneeva, O. V. (2001). Ispolzovanie spetsialnyih poznaniy $v$ dokazyivanii na predvaritelnom sledstvii. Uchebnoe posobie. Saratov: SGAP.

8. Paliashvili, A. Y. (1973). Ekspertiza $v$ sude po ugolovnyim delam. M..

9. Aliev, I. A. (2010). Provedenie ekspertizyi v ugolovnom protsesse. B.: Gosudarstvennoe izdvo "Yuridicheskaya literatura".

10. Eksarhopulo, A. A. (2005). Spetsialnyie poznaniya $i$ ih primenenie $v$ issledovanii materialov ugolovnogo dela. SPb. 


\begin{tabular}{llllll} 
& ISRA (India) $=\mathbf{3 . 1 1 7}$ & SIS (USA) $=\mathbf{0 . 9 1 2}$ & ICV (Poland) & $\mathbf{= 6 . 6 3 0}$ \\
Impact Factor: & ISI (Dubai, UAE) $=\mathbf{0 . 8 2 9}$ & PUHL (Russia) $=\mathbf{0 . 1 5 6}$ & PIF (India) & $=\mathbf{1 . 9 4 0}$ \\
& GIF (Australia) $=\mathbf{0 . 5 6 4}$ & ESJI (KZ) & $\mathbf{5 . 0 1 5}$ & IBI (India) & $=\mathbf{4 . 2 6 0}$ \\
& JIF & $\mathbf{1 . 5 0 0}$ & SJIF (Morocco) $=\mathbf{5 . 6 6 7}$ & & \\
\hline
\end{tabular}

